\title{
The Role of Gender and Marital Status in the Perception ofPersonalization and Visualization in Hybrid Advertising
}

\author{
Lyubomira Spasoova* \\ Department of Social Sciences and Business Language Training, Bulgaria
}

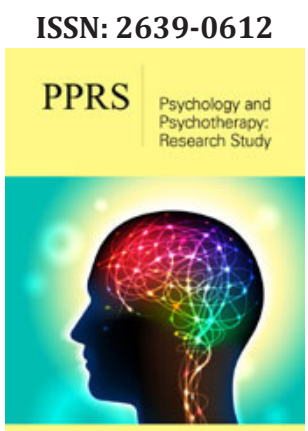

*Corresponding author: Lyubomira Spasoova, Department of Social Sciences and Business Language Training, Bulgaria

Submission: 侮 September 06, 2021

Published: 踇September 24, 2021

Volume 5 - Issue 2

How to cite this article: Lyubomira Spasoova*. The Role of Gender and Marital Status in the Perception of Personalization and Visualization in Hybrid Advertising. Psychol Psychother Res Stud. 5(2). PPRS. 000606. 2021. DOI: 10.31031/PPRS.2021.05.000606

Copyright@ Lyubomira Spasoova, This article is distributed under the terms of the Creative Commons Attribution 4.0 International License, which permits unrestricted use and redistribution provided that the original author and source are credited.

\begin{abstract}
The role of gender and the changes that occur with it are the subject of many psychological, sociological, behavioural and political sciences, which makes the topic relevant today. The current research measures the role of gender and family status of 398 respondents, as well as their reactions to hybrid advertising as part of the personalization and visualization of the products and services offered. The results show that a positive response is given by the respondents regarding advertisements with increased presence of men and women and impactful visualization, compared to those in which persons of both sexes are not present. The applicability of the research is important for the organizations that created the respective advertisements, because the connection between the susceptibility of the respondents to characters in the advertisement is deduced, which leads to extreme reactions.
\end{abstract}

Keywords: Gender; Personal and visual effect; Impact of advertising

\section{Introduction}

Persuasive advertisements use a wide variety of figures, images, characters and verbal cues that determine the perception, memory and successful impact of the products and services offered. Therefore, the role of gender in our society has changed dramatically [1], with images of men and women in advertising becoming the subject of research in many areas [2]. The main task is to evaluate these roles in advertising in order to explain how advertising influences social stereotypes and gender changes. The other important dimension is how men and women perceive and interpret advertisements based on the portrayal of gender roles. Recent research shows that the idealized images of physical attractiveness found in advertising have a negative impact on perceptions of girls and women [3], while other studies confirm that the portrayal of gender roles in advertising has not become more genderneutral, which deepens men's confusion about what male roles are expected of them after they appear in commercials [2]. Men and women today lead extremely complex lives with many social roles [1]. Regarding the performance of roles, it was found that images range from images in the inactive period of audiences, where women are hosts and mothers, and men working and successful, to ads broadcast in primetime, where the images are more balanced [4]. Internationally, advertising is still in line with traditional gender images [5], with more dependence on women than men. The present study aims to examine the role of gender and family status of consumers in the perception of personalization and visualization in advertising, looking for dependencies on the presentation of images in advertising, as well as the perception of these images as a manifestation of certain consumer behaviour.

\section{Theoretical Background}

The selection of information from advertising, its processing and overall impact are subject to consideration by marketers, advertisers, psychologists and sociologists, because they determine specific personality traits of men and women related to the formation of social roles of gender, as well as ways of perception of the surrounding world. Major differences are found in the verbal perception of advertisements, with studies showing that women do better at decoding nonverbal signals [6-8] compared to men who are more likely to perceive advertising in general-verbal and visual information as a whole [9]. In addition, men and women appear to give different weight to prominent attributes $[10,11]$ 
and sources of information when evaluating products [12] cited by: [8]. On the other hand, the emergence of stereotypes in advertising can be understood as a way to simplify the requirements for the perception of information [13], allowing recipients to rely on pre-stored knowledge instead of making sense of new input and reacting in a new way to different social roles [14]. Therefore, modern advertisers are faced with the question of choosing an ad in which either gender plays stereotypical roles or reveals new gender differences that would cause different ways of perceiving information. The Social Role Theory [15] suggests that the malefemale differences in aptitude and personality traits often reflect traditional gender roles in society.

Based on some social and biological factors, stereotypes for women are associated with some emotional, expressive and interpersonal self-esteem, while those for men outnumber women in instrumental and age-oriented stereotypes [16], so it is normal for them to occupy different social roles and be subjected to of different social pressures [17]. Stereotypes are created by the continual, extended exposure of consumers to patterns of imagery, as in modern advertisements gender mixing is almost not allowed [1]. According to social pressure, men traditionally assume more dominant roles and women assume relatively submissive and subordinate roles [18]. Due to the disadvantage in some societies, women are more sensitive to non-verbal signals in messages and images.

They have increased needs and motives to understand the subtle interpersonal cues to help them in social adaptation $[6,14,15]$. A meta-analysis of global advertising [19] found that women are much more likely to be presented as addicted to advertising and much more likely to be represented at home than men. This dependence is also found in their interaction with the advertised products and services, women are also seen as more tactile than men; that is, they more often are touching, cradling, and caressing objects. This suggests the more passive nature of women in advertising. Similarly, women tend to appear removed from the social situation of the activity pictured in advertising [20]. Women are also seen as more tactile than men; that is, they more often touch and caress objects [1]. This suggests a more passive nature of women in advertising. Similarly, women tend to appear removed from the social status of the activity depicted in the advertisement [1].

Goffman's findings include that women are generally pictured at a smaller relative size, especially height [20]. Men tend to be pictured as taller than women, putting them in a position of power, authority, and rank in the advertisements [1]. Therefore, the presence of men and women in advertising can determine the ways of perceiving personal and visual messages from it and build different ideas as a link between the products and services offered and the roles of the sexes in advertising. In recent years, traditional sexual roles have changed significantly in Western societies due to more enlightened attitudes and a greater number of women entering the workforce. In fact, in two meta-analyses spanning six decades, the assertiveness of American women increases and decreases with their education and job roles [21]. The change of roles is also found in the emancipation of women-working, active and confident, as well as in the presence of male housewives, fathers, parents in various media channels. For example, ads in China show women as workers, not as housewives, contrasting with women in ads in other Asian cultures, such as ads in South Korea and Thailand [1].

In addition, aspects of the Cultural Revolution minimize the visual differences between men and women. Some countries, such as Malta, have developed guidelines for gender equality in the media [22]. Other researchers have found that the images of men and women in advertisements are inaccurate, and this can create problems in the perception and accurate understanding of gender roles. A study by advertising agency Leo Burnett found that $80 \%$ of men believe that men's media images are inaccurate. The interaction between the offered product and the role of the characters in advertising has not been sufficiently studied, so in the present study an attempt is made to fill this gap by offering TV and online advertisements to respondents of both sexes, with different marital status, looking for dependencies. between the presence of characters in the advertisement and the reactions of respondents of both sexes.

\section{Research Design and Methodology}

The present study measures the degree of receptivity of respondents to the personalization and visualization of hybrid advertising, i.e., advertising, i.e., advertising that is based on impression and based on the effectiveness or a combination of both. 398 respondents from Bulgaria, Greece, Macedonia, Ukraine, Turkey, Russia, Ireland, England, Italy, Spain aged 18 to 55 were surveyed, with an average age of 38 years. Apart from gender, the respondents are also divided by marital status, and each of them is given the opportunity to watch advertisements in print, electronic media and on the Internet. Advertisers are well-known companies such as: Versace, Vogue, Dolce \& Gabbana, Nike, Puma, Woman \& Home, Louis Vuitton and others, respondents rate images of online and TV commercials with or without characters of both sexes, i.e. only the offered product or service. 68 different advertisements promoted during the period from 2014 to 2021 were studied. A five-point Likert psychometric scale is applied, which includes the following degrees: Disagree, slightly disagree, Neutral, slightly agree, Agree [23]. The higher the degree of agreement found in a respondent on the Likert scale, the more convincing is the personalization and visualization of the advertisement, with the aim of establishing the role of gender in each advertisement. A closed survey was used with complete anonymity of the answers, consisting of 128 questions for the whole survey, as the questions were presented to the respondents and asked to give their opinion.

The method for gathering information is a questionnaire, which contains the following modules: 
1. First Module-Demographic characteristics;

2. Second Module-STPS questionnaire or Susceptibility to Persuasion Strategies Scale, developed by Kaptein M et al. [24] to determine the propensity of respondents to advertising influence;

3. Third Module: Advertisements with visualization of products and services without the presence of characters;

4. Fourth module-Advertisements with visualization of advertisers of both sexes.

The presentation of the data from the empirical study with the indicated parameters aims to illustrate the consumer consumption regarding different products and services, by establishing the impact of the characters. Based on the theoretical framework, the following hypotheses can be made:

$\mathrm{H}_{0}$-The visualization and personalization in advertisements of different companies does not affect the perception of their advertisements and cannot determine the use of the offered products and services.

$\mathrm{H}_{1}{ }^{\mathrm{a}}$-The visualization and personalization in advertisements of different companies influences the perception of their advertisements by women and this can determine the use of the offered products and services.

$\mathrm{H}_{1}{ }^{\mathrm{b}}$-The visualization and personalization in advertisements of different companies influences the perception of their advertisements by men and this can determine the use of the offered products and services.

\section{Empirical Result and Discussion}

In this study, the advertisements of the following groups are distributed in advance:

1. First factor - Advertisements with product visualization;

2. Second factor - Advertisements with visualization of male products and characters;

3. Third factor - Advertisements with visualization of female products and characters;

4. Fourth factor - Advertisements with visualization of male and female products and characters.

The survey involved 398 respondents, of whom 51.1\% were men (195 people) and 48.9\% were women (203 people). In order to establish the factor structure of the questionnaire, the factor analysis with rotations from Warimex was applied. Four factors have been derived in which the above combinations exist. In order to achieve greater specificity in the product category, data from the impact of Vogue, Versace and Dolce \& Gabbana ads are provided. The publication presents the factors with the highest values (Table 1).

The first factor-ads with product visualization has an internal consistency of Cronbach's Alpha 0.71 , which we consider relatively acceptable, and the factor-ads with visualization of male products and characters has an internal consistency of Cronbach's Alpha 0.79 , which we consider acceptable. The third factor-ads with visualization of products and female characters has a consistency with a relatively high to strong consistency Cronbach's Alpha 0.81 , which shows that the visualization of women in ads affects consumers significantly more than the visualization of men in ads from the same product category. Table 1 also shows the results of the fourth factor-ads with the presence of characters and product positioning, as the consistency has the highest values of Cronbach's Alpha 0.88, which is evidence of the strong influence of the characters on the recipients of advertising, which help perception and the impact of the products offered. In order to establish the relationships between the gender of the respondents and the gender of the characters, an analysis of the variance, denoted as ANOVA, is performed. A series of ANOVAs was conducted comparing the mean scores of men and women on the dependent variables to test the hypotheses. The corresponding one-dimensional comparisons are presented in Table 2.

Table 1: Factor structure.

\begin{tabular}{|c|c|c|c|c|}
\hline Factor structure & $\begin{array}{l}1 \text { Factor } \\
\text { Cronbach's } \\
\text { Alpha } 0.71\end{array}$ & $\begin{array}{l}2 \text { Factor } \\
\text { Cronbach's } \\
\text { Alpha } 0.79\end{array}$ & $\begin{array}{l}3 \text { Factor } \\
\text { Cronbach's } \\
\text { Alpha } 0.81\end{array}$ & $\begin{array}{c}4 \text { Factor } \\
\text { Cronbach's } \\
\text { Alpha } 0.88\end{array}$ \\
\hline $\begin{array}{c}\text { Informative advertising of Versace Eros -The new fragrance for } \\
\text { men }\end{array}$ & 0.69 & - & - & - \\
\hline Informative advertising of Versace Pour Femme for women & 0.73 & & & \\
\hline Vogue’s aggressive advertising in Italy since 2017, Bacio & - & 0.71 & - & - \\
\hline $\begin{array}{l}\text { The aggressive advertising of Versace Eros with Brian Shimansky } \\
\qquad(2017)\end{array}$ & - & 0.88 & - & - \\
\hline $\begin{array}{l}\text { The informative advertisement of Vogue in British magazine from 2018, } \\
\text { New Frontiers }\end{array}$ & - & & 0.79 & - \\
\hline $\begin{array}{l}\text { The aggressive advertising of Versace Eros Pour Femme with } \\
\text { Lara Stone }\end{array}$ & - & - & 0.84 & - \\
\hline The aggressive Vogue ad offered in the US in 2014 with Gisele \& LeBron & - & - & - & 0.76 \\
\hline
\end{tabular}




\begin{tabular}{|c|c|c|c|}
\hline The informative advertisement of Vogue with Justin \& Hailey from 2019 & - & - & - \\
\hline $\begin{array}{c}\text { The aggressive advertisement of Dolce \& Gabbana with David } \\
\text { Gandy \& Bianca Balti }\end{array}$ & - & - & - \\
\hline $\begin{array}{c}\text { The aggressive advertisement of Vogue with Kim \& Kanye, of- } \\
\text { fered in the USA in 2014 }\end{array}$ & - & - & - \\
\hline
\end{tabular}

Table 2: Influence of gender on advertisements.

\begin{tabular}{|c|c|c|c|c|c|}
\hline \multirow{2}{*}{ Dependent Variable } & \multicolumn{2}{|c|}{$\begin{array}{c}\text { Mean (SD) } \\
\text { Men Women }\end{array}$} & F Value & $\begin{array}{c}\text { P Value } \\
\text { (One-Sided) }\end{array}$ & $\begin{array}{c}\text { Personalized/ Visualized } \\
\text { Advertisements }\end{array}$ \\
\hline Total number of responses for ads with products & $54.3(7.1)$ & $79.0(7.2)$ & 4.19 & 0.04 & Visualization \\
\hline Total number of responses for ads with men and products & $21.7(3.4)$ & $31.2(3.6)$ & 3.14 & 0.01 & Personalization \\
\hline Total number of responses for ads with women and products & $0.25(.02)$ & $0.29(.02)$ & 2.87 & 0.03 & Personalization/Visualization \\
\hline Total number of responses for ads with men, women and products & $0.43(.02)$ & $0.39(.02)$ & 3.56 & 0.05 & Personalization \\
\hline
\end{tabular}

According to the hypotheses, four variables were created, and the data obtained from the respondents are presented in Table 2. Hypothesis $\mathrm{H}_{0}$ can be rejected because statistically significant results are derived with respect to the dependent variable-Total number of responses for ads with men and products, such as values in women are higher-Mean (SD)=31.2 (3.6), F (2,396) =4.19, p <0.01 compared to values in men Mean (SD)=21.7 (3.4), $F(2,396)=4.19$, $\mathrm{p}<0.01$. In addition, statistically significant results were also found in the dependent variable - Total number of responses for ads with men, women and products, and again the values in women are higher - Mean $(S D)=0.39(.02), F(2,396)=3.56, p<0.01$ compared to values in men Mean (SD) $=0.43(0.2), F(2,396)=3.56, p<0.01$.

Hypotheses $\mathrm{H}_{1}{ }^{\mathrm{a}}$ and $\mathrm{H}_{1}{ }^{\mathrm{b}}$ concern measures for the perception of advertisements with the presence of characters, finding dependencies on the male and female presence. The results show that, on average, women are more likely to perceive personalization in advertising, compared to men, measured by the presence of visual and character elements in advertising. These results support Hypotheses $\mathrm{H}_{1}{ }^{\mathrm{a}}$ and $\mathrm{H}_{1}{ }^{\mathrm{b}}$ by affecting the influence of gender on personalization, but not so much on product visualization. Female respondents are more strongly influenced by the presence of the characters, regardless of their gender, than male respondents. In order to establish new dependencies between the gender and family status of the respondents on the personalization and visualization in advertising, a new series of ANOVA on the dependent variables is conducted, comparing the average results of respondents with different marital status. The corresponding one-dimensional comparisons are presented in Table 3.

Table 3: Influence of marital status on advertisements.

\begin{tabular}{|c|c|c|c|c|c|}
\hline Dependent Variable & \multicolumn{2}{|c|}{$\begin{array}{c}\text { Mean (SD) } \\
\text { Married Single }\end{array}$} & F Value & $\begin{array}{c}\text { P Value } \\
\text { (One-Sided) }\end{array}$ & $\begin{array}{c}\text { Personalized/Visualized } \\
\text { Advertisements }\end{array}$ \\
\hline Total number of responses for ads with products & $32.3(5.1)$ & $39.1(6.3)$ & 2.11 & 0.03 & Visualization \\
\hline Total number of responses for ads with men and products & $4.10(2.6)$ & $5.39(2.9)$ & 3.14 & 0.01 & Personalization \\
\hline Total number of responses for ads with women and products & $1.29(.03)$ & $1.19(.03)$ & 2.87 & 0.05 & Personalization/Visualization \\
\hline Total number of responses for ads with men, women and products & $0.38(.02)$ & $0.28(.02)$ & 3.17 & 0.05 & Personalization \\
\hline
\end{tabular}

The obtained statistically significant results show that the dependent variable - Total number of responses for ads with products, in which the average value in married respondents is lower Mean (SD) = 32.3 (5.1), F(2,396)=2.11, p <0.05, and for single respondents is higher Mean $(\mathrm{SD})=39.1(6.3), \mathrm{F}(2,396)=$ $2.11, \mathrm{p}<0.05$, confirm the view that single respondents are more strongly influenced by advertising promoting a product with visualization. The table also shows the predominant influence of personalization on dependent variables: Total number of responses for ads with men and products, Total number of responses for ads with women and products and Total number of responses for ads with men, women and products, which also is in support of personalization versus visualization. High values were reported in married respondents regarding the dependent variable-Total number of responses for ads with women and products, where the mean values were Mean $(\mathrm{SD})=1.29(.03), \mathrm{F}(2,396)=2.87$, $\mathrm{p}<0.05$, relative to single respondents, where Mean (SD) $=1.19$ (.03), $\mathrm{F}(2,396)=2.87, \mathrm{p}<0.05$, therefore married respondents are influenced by the presence of women in advertising as part of personalization. Regarding dependent variable - Total number of responses for ads with men, women and products high values are in married respondents Mean (SD) = $0.38(.02), F(2,396)=3.17, p$ $<0.05$, compared to single respondents Mean (SD) $=0.28(.02), \mathrm{F}$ $(2,396)=3.17, p<0.05$, therefore the male and female characters in the advertisement can influence the perception and reactions of married respondents. 


\section{Conclusion}

The study of the sexes, their differences, as well as their visual presentation in the advertisements of the various media, is a modern process that must be constantly monitored and analysed. The results of the study show that women are strongly influenced by ads for various products and services, and the values are even higher in the presence of characters in advertising. A comparison with another recent study on positive and negative advertising responses can be established, but this is not the aim of the present study $[25,26]$. Men also show some propensity to perceive ads with characters, with the highest values reported for ads with the presence of both sexes. The statement of Fischer \& Arnold [10] that men and women give different weight to the products offered is confirmed, as women appreciate perfumes, women's accessories and other accessories in advertising, and men are interested in the benefits, duration of use and durability of some sport goods.

The dependence of each of the sexes in the advertisement is analysed, and the results show that the female characters have a greater influence in the advertisement than the male characters. Gender neutrality in advertising is achieved by the characters dressed as ancient Greek gods, especially the Vercace advertisements. In other advertisements, such as Vogue magazine, this neutrality is not present, and the results show that portraying a man as a strong, athletic person provokes a positive reaction in male respondents. In addition, through Vogue and Dolce \& Gabbana ads, the relationship between a man and a woman, regardless of which gender has a dominant or passive role, has the greatest impact among respondents who even declare a change or willingness to change their behaviour. Regarding marital status, single respondents stated a greater interest in ads without personalization, as well as in ads with the presence of men. For their part, married respondents give a positive advertising response when women or characters of both sexes are present in the advertisement, from which it can be concluded that they find dependencies between married couples and couples in the advertisements of different organizations.

The limitations of the study are the fact that the relationship between the nationality of the respondents and the origin of the advertisements in the different countries has not been studied. In addition, the stereotypical influence in advertising, as well as the reactions of the respondents to certain stereotypes, have not been proven. In addition, the dependencies between the marital status of the respondents, their satisfaction with the use of products and services, as well as established benefits for each of the two sexes are not presented. For the following studies, studies on the visualization, verbalization and other aspects of the personalization of each advertisement may be recommended, with an emphasis on the clothing, posture, race of the characters, causing different reactions in the subjects. Researchers are also extremely interested in issues related to gender inequality, racial differences and perceptions of both sexes, as well as some reactions of certain social groups regarding homosexual and bisexual behaviour.

\section{References}

1. Sheehan K (2012) Controversies in contemporary advertising. In: Baeza $\mathrm{S}$ (Ed.), Gender and advertising-how gender shapes meaning, Chapter 7, Academia, Sage Knowledge, pp. 89-111.

2. Gentry J, Harrison R (2010) Is advertising a barrier to male movement toward gender change? J Mark Theory 10(1): 74-96.

3. Gulas CS, McKeage K (2013) Extending social comparison: An examination of the unintended consequences of idealized advertising imagery. Journal of Advertising 29(2): 17-28.

4. Craig RS (1992) The effect of television day part on gender portrayals in television commercials: A content analysis. Sex Roles 26(5/6): 197-211.

5. Paek HJ, Nelson MR, Vilela AM (1992) Examination of gender-role portrayals in television advertising across seven countries. Sex Roles 64: 192-207.

6. Hall JA (1984) Nonverbal sex differences: communication accuracy and expressive style. Johns Hopkins University Press, Baltimore, USA, pp. 1245 .

7. Everhart DE, Shucard JL, Quatrin T, Shucard DW (2001) Sex-related differences in event-related potentials, face recognition, and facial affect processing in prepubertal children Neuropsychology 15(3): 329-341.

8. Putrevu S, Gentry JW, Fisher E (2014) Exploring the origins and information processing differences between men and women: Implications for advertisers. Social Psychology. Consumer Culture and Neoliberal Political Economy 3: 82-89.

9. Levy MJ, Sternthal B (1991) Gender differences in the use of message cues and judgments. Journal of Marketing Research 28(1): 84-96.

10. Fischer E, Arnold SJ (1994) Sex, gender identity, gender role attitudes, and consumer behaviour. Psychology \& Marketing 11(2): 163-182.

11. Holbrook M (1986) Aims, concepts, and methods for the representation of individual differences in aesthetics responses to design features. Journal of Consumer Research 13(3): 337-347.

12. Levy MJ (1988) Influence of sex roles on judgment. Journal of Consumer Research 14(4): 522-530.

13. Macrae CN, Milne AB, Bodenhausen GV (1994) Stereotypes as energysaving devices: A peek inside the cognitive toolbox. Journal of Personality and Social Psychology 66 (1): 37-47.

14. Eagly AH (1995) The science and politics of comparing women and men. American Psychologist 50(3): 145-158.

15. Eagly AH, Wood W (2012) Social role theory. In: Van Lange P, et al. (Eds.), Handbook of theories in social psychology. pp. 458-476.

16. Costa PT, Terracciano A, McCrae RR (2001) Gender differences in personality traits across cultures: Robust and surprising findings. Journal of Personality and Social Psychology 81(2): 322-331.

17. Taylor MC, Hall JA (1982) Psychological androgyny: Theories, methods, and conclusions. Psychological Bulletin 92(2): 347-366.

18. Moschis GP (1985) The role of family communication in consumer socialization of children and adolescents. Journal of Consumer Research 11(4): 898-913.

19. Paek HJ, Nelson MR, Vilela M A (2001) Examination of gender-role portrayals in television advertising across seven countries. Illinois Experts 64(3): 192-207.

20. Goffman E (1879) Gender advertisements. Harper \& Row Publishers Inc, New York, USA, 10022.

21. Twenge JM (2001) Changes in women's assertiveness in response to status and roles: A cross-temporal meta-analysis, 1931-1993. Journal of Personality and Social Psychology 81(1): 133-145. 
22. Livia SZO, Richter R, Kotowska IE (2017) The new roles of men and women and implications for families and societies. A Demographic Perspective on Gender, Family and Health in Europe pp. 41-64.

23. Sacks G, Smaglick R (2008) Advertisers: Men are not idiots. Ad Age 79: 44.

24. Kaptein M, Markopoulos P, Ruyter B, Aarts E (2009) Can you be persuaded? Individual differences in susceptibility to persuasion. IFIP Conference on human-computer interaction, LNCS, 5726: 115-118.
25. Spasova L (2021) Main dependences between gender, financial status and indicators predicting purchase of mobile products and services in Bulgaria. Sixth International Scientific Conference. Business and Regional Development SISC, SHS Web of Conferences 120: 04005.

26. Spasova L, Taneva T (2021) Influence of gender on advertising responses of young people for products of mobile operators in Bulgaria. Sixth International Scientific Conference. Business and Regional Development SISC, SHS Web of Conferences 120: 04002. 